\title{
Studies assess risks of drugs in water cycle
}

Quirin Schiermeier, Gothenburg

Antibiotics and other pharmaceuticals given to humans and livestock are increasingly contaminating rivers, groundwater and soils, according to early results from three European studies.

Drug-contaminated waste water is a potential risk to both human health and the environment, the studies' participants say. Treating sewage with ozone would be the best way of cutting the drug residues, they suggest.

Groups behind the three European Union-funded studies released their results at a Gothenburg press conference on 27 June. They reported that high concentrations of excreted antibiotics have been found in hospital and household sewage, slurry and water used for irrigation. Antibiotics and their metabolites also reach the environment directly from the urine and faeces of farm animals, the scientists find.

Researchers worry that the growing levels of antibiotics in the environment may damage ecosystems and fuel a surge in antibiotic

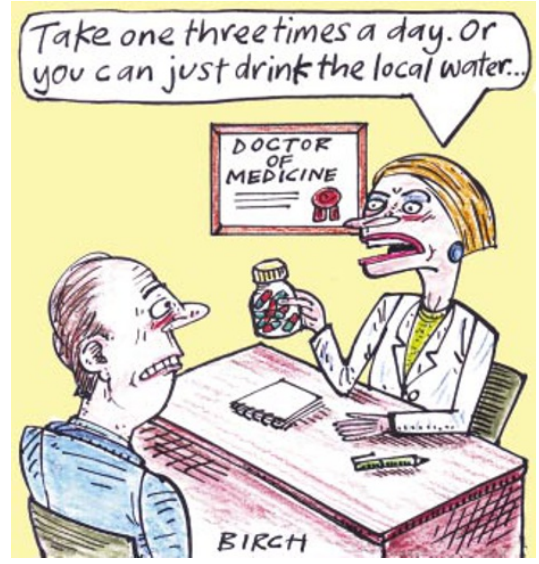

resistance among humans and animals. "Antibacterial resistance from farm animals can be transferred to humans, and is increasingly threatening the effective management of infectious diseases," says Wolfgang Witte, a microbiologist at the Robert Koch Institute in Wernigerode, Germany.

Officials at the European Union say the studies, and other similar ones, are likely to form the basis of new management procedures for medicines. Water companies and hospitals could also be required to take further steps to extract antibiotics from certain stages of the water cycle. This could be done, for example, by using separation techniques on the urine from hospital patients, and by injecting ozone into effluent at sewage plants.

Scientists involved in one of the projects, called Poseidon, found 35 pharmaceutical compounds, including five antibiotics, in the effluent of a local sewage plant in Braunschweig, Germany, and in local rivers. Concentrations in the effluent reached several micrograms per litre, with those in rivers and groundwater measuring 1.0-2.5 micrograms per litre, depending on the compound. Measurements taken at sewage plants in Poland, Switzerland, France and Austria revealed similarly high drug concentrations.

"Concentrations were particularly high in small rivers and streams that take a large amount of municipal waste water," says Thomas Ternes, a chemist at Germany's Federal Institute of Hydrology, and project coordinator of Poseidon.

In a parallel project, called ERAVMIS, researchers in Denmark, the Netherlands, Britain and Spain assessed the fate of veterinary medicines in slurry, made from manure, that is applied to the land as fertilizer.

Department of Health and Human Services.

In response, AFIP leaders told their staff this spring that they plan to save $\$ \mathbf{6 . 6}$ million a year by eliminating more than 100 jobs, and to slash the institute's \$3.5-million rent bill by closing three of its five facilities. They also decided to raise consultation and training fees, so that by 2004 the AFIP's military responsibilities would outweigh its civilian workload.

But AFIP staff claim that they were not consulted on the proposed changes, and many are strongly opposed to them. "I understand they had to make cuts but the way they proposed to do it was just malicious," says Renu Virmani, chair of cardiovascular pathology at the institute. Critics add that the plan will damage the AFIP's ability to retain expert pathologists by restricting its activities in non-military research.

Renata Greenspan, a pathologist at the Walter Reed Army Institute of Research who became director of AFIP in May, is re-evaluating the business plan, and says that she has worked hard to include the institute's staff in the process. She says that she has not determined what combination of staff reduction, rent cuts and increased charges will be necessary, and expects to present a new plan to the AFIP's divisional heads at the end of this month.

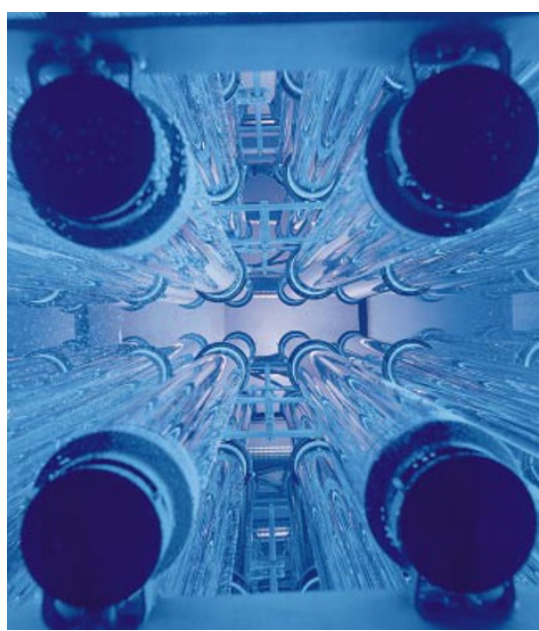

Ozone treatment such as that used on drinking water (above) could strip drugs from sewage.

They found that tetracyclines, a group of antibiotics widely used in livestock, cling to soil, degrading slowly. Concentrations remained high six months after application.

A third project, carried out by researchers in Sweden, Greece, Italy and France, also monitored effluents from sewage plants.

"There is clear evidence that some veterinary antibiotics persist in soils, and can move to rivers and streams and enter groundwater," says Alistair Boxall, an environmental chemist at Cranfield University, UK, and project coordinator of ERAVMIS.

The environmental effects of these compounds remain unclear, however. Researchers found no acute toxic effects on crops, worms, insects or fish. But they did find adverse effects on soil bacteria and some aquatic plants.

"Antibiotics can change the growth, enzyme activity and diversity of soil microbes," says Boxall. This may lead to a larger ecological problem, he adds, "but we don't know how big it is". More research is needed to determine whether microbial pathogens are becoming resistant to standard antibiotics, he says.

One recent analysis of raw sewage at the University Hospital of Würzburg, Germany, found that concentrations of antibiotics were not high enough to allow the selection of pathogenic bacteria resistant to them (K. Ohlsen et al. Environ. Microbiol.; in the press). But risks cannot be discounted on the basis of this result, says study co-author Thomas Ternes, a chemist at Germany's Federal Institute of Hydrology in Koblenz.

Ternes, the project coordinator of Poseidon, suggests that 'ozonation' of sewage is the most efficient way to eliminate unwanted residues. Ozone can be readily extracted from air, and it breaks down $99 \%$ of antibiotics and other drugs, he says. 